\title{
A Experiência Religiosa como Prática Terapêutica: Estudo de CASO DE UM Terreiro de Umbanda com Santo Daime
}

\section{Maria Beatriz Lisboa Guimarães ${ }^{\perp}$}

\section{Resumo}

Este trabalho consiste no estudo de caso de um terreiro de Umbanda, localizado no Rio de Janeiro, onde se constata a união com a religião do Santo Daime. Este terreiro possui características peculiares que, por um lado, comprovam a visão geral que se tem da Umbanda como sendo um sistema religioso sincrético, maleável e inclusivo. Por outro lado, reflete a visão de mundo de um grupo de indivíduos pertencentes, em sua grande maioria, às camadas médias intelectualizadas do Rio de Janeiro. 0 objetivo do trabalho foi buscar o sentido da experiência religiosa não-convencional presente nos rituais da Umbanda e do Santo Daime. Constatou-se que a procura por estas práticas simbólico-religiosas, na maior parte dos casos, está inserida em uma busca de autoconhecimento que inclui diferentes práticas terapêuticas alternativas.

Palavras-chave: Práticas terapêuticas alternativas, Cura, Umbanda, Santo Daime

\section{Abstract}

This is a study about an Umbanda center in Rio de Janeiro, where a union with the Santo Daime religion takes place. This Umbanda center presents some peculiar characteristics, which, in a way, prove the common point of view about Umbanda as a syncretic, flexible and inclusive religious system. On the other hand, it reflects the world vision of an intellectualized middle-class group of people from Rio de Janeiro. The objective of this study consisted in investigating the meaning of non-conventional religious practices presented in Umbanda and Santo Daime's religious centers. The results point out that the search for these symbolic religious practices in most cases is directly related to the search for self-knowledge through alternative therapeutic practices.

Keywords: Alternative therapeutical practices, healing, Umbanda, Santo Daime.

\footnotetext{
${ }^{1}$ Doutora em Saúde Coletiva - Instituto de Medicina Social/UERJ email: beatriz.guima@ensp.fiocruz.br
}

Revista Mediaçóes, Londrina, v. 11, N. 2, p. 45-64, Jul./Dez. 2006 
Senhora da Paz

Senhora da Paz, vem ver

Os seus filhos sobre a Terra

Os seus filhos sobre a Terra

Todos são iguais

Todos são iguais

Ao Pai

Quem trabalha é uma estrela

Verde, azul e branca

Firmada no astral

Reinado do Sol

Venha nos curar

Santo Daime e Umbanda para trabalhar

Jagube, Rainha, homem, fogo e água

Sol, Lua e Estrela para se firmar

("Hino" do Santo Daime)

\section{INTRODUÇÃO}

0 presente artigo apresenta e discute os resultados da pesquisa antropológica realizada em um terreiro de Umbanda situado na zona sul do Rio de Janeiro. A escolha deste terreiro mostra-se bastante interessante, devido ao encontro de duas tradições nascidas no Brasil - a Umbanda e o Santo Daime - tendo sido configurado como um caso único do encontro dessas tradições e que apresenta, portanto, características singulares ainda não pesquisadas pelas ciências sociais. São tradições tipicamente brasileiras, sincréticas, onde se congregam elementos do Cristianismo, do Espiritismo e das tradições afro-brasileiras. Ambas se caracterizam ainda como um sistema de crenças em formação, não se apresentando como um sistema acabado, pronto e fechado; talvez por isso mostrem-se capazes de incorporar recortes de outras tradições.

Tanto do ponto de vista sociológico quanto do ponto de vista cultural, esse terreiro apresenta muitas peculiaridades. Em termos sociais, além do encontro ressaltado acima, temos ainda a inserção de uma outra prática simbólica de cura, que são os cristais. Soma-se a isto o fato da mãe-de-santo do terreiro ter como atividade profissional a massagem terapêutica. Em termos culturais, esse terreiro se apresenta como uma teia simbólica, na qual tratar-se-ia de desvendar como os indivíduos envolvidos lidam e redefinem este conjunto complexo de códigos, aparentemente distintos, mas que asseguram a ação coletiva do grupo. 
0 tema dessa pesquisa se insere num contexto mais amplo - das práticas terapêuticas alternativas -, presente entre segmentos da classe média, que começou a ter um peso maior a partir dos anos 1960 com o movimento da contracultura. Com 0 movimento hippie teve início um retorno à busca do sagrado entre jovens da classe média dos EUA, cuja repercussão foi ampliada por todo o Ocidente, chegando até 0 Brasil. Esse movimento não se caracterizava pela procura de uma religião em particular, mas dizia respeito, muito mais, à religiosidade de um modo geral, ou ainda a comportamentos coletivos que possuem uma manifesta dimensão espiritual (MENEZES, 1988).

0 despertar para o sagrado não tem em si nada de novo. A novidade que vem ocorrendo nos últimos 30 anos é o peso de sua manifestação como moda cultural, tanto entre indivíduos de camadas médias dos grandes centros urbanos como entre as classes populares. É bom destacar que, ao contrário do que vem ocorrendo com parte da classe média intelectualizada, que durante um período de tempo, se distanciou das práticas religiosas, as classes populares sempre mantiveram uma cosmovisão sagrada do mundo, próxima da tradicional. (LUZ, 1996).

Apesar da maior parte da sociedade brasileira ser constituída de católicos, como atestam os censos oficiais, é grande o número de fiéis que recorrem a centros espíritas, terreiros de Umbanda, Candomblé e, mais recentemente, a cultos evangélicos pentecostais e neo-pentecostais. Isto contribui para reforçar a percepção de que a crença em espíritos é, de certa maneira, generalizada em nossa sociedade (VELHO, 1994), entretanto, ela é capaz de assumir diferentes formas, dependendo do contexto social e cultural em que é absorvida.

Finalmente, para chegarmos ao objeto desta pesquisa, é crescente também 0 número de indivíduos de camadas médias do Rio de Janeiro que aderem a alguma religião, e principalmente a religiões não-convencionais - entre as quais se incluem as provenientes das tradições orientais, as religiões afro-brasileiras, aqui representada pela Umbanda, e o Santo Daime - e não às religiões mais tradicionais do país - Catolicismo, Judaísmo e Protestantismo -, nas quais esses indivíduos foram criados ou socializados primariamente. Segundo Jurandir Freire Costa (1984), em geral a religião católica é vista como culpabilizante e repressora, enquanto que estas outras têm um efeito de liberação da vontade, ou de uma busca de autonomia.

A perspectiva do presente trabalho foi buscar o sentido da experiência religiosa não-convencional, compreendendo a experimentação como uma questão central que articula os pontos de vista ético, cultural, religioso e político e que permite assim demarcar a religião em si mesma como produtora de significados. Dentro deste contexto, procurei me deter nas práticas terapêuticas simbólico-religiosas, na medida em que a 
minha hipótese de trabalho visou demonstrar que a procura por estas práticas está inserida em uma busca de autoconhecimento.

\section{Algumas Considerações sobre a Umbanda}

Atualmente, podemos constatar que na Umbanda encontra-se um maior predomínio das camadas populares, passando a fazer parte dos estudos que abordam as produções culturais destas classes. Creio que esta pesquisa pode lançar uma nova luz sobre estes estudos, ao mesmo tempo em que retoma a formação primordial da Umbanda, ao lidar com o universo de camadas médias, constituída de terapeutas, intelectuais, artistas entre outros que, de uma forma ou de outra, têm acesso à cultura oficial e por motivos diversos optam por formas "alternativas" de cura, como no caso em questão. É nesse sentido que creio poder ajudar a complexificar a relação estabelecida entre cura "mágica" na Umbanda e classe social. (LOYOLA, 1984; MONTERO, 1985).

De acordo com Diana Brown (1985), a Umbanda foi fundada por iniciativa de um grupo de kardecistas de classe média que começou a incorporar tradições afrobrasileiras a suas práticas religiosas. Esse grupo de indivíduos fundadores da Umbanda, homens e quase todos brancos, passou a preferir os espíritos e divindades africanas e indígenas presentes na "macumba", em detrimento dos espíritos considerados por eles como mais evoluídos do kardecismo, para a cura e o tratamento de doenças diversas. No entanto, repudiavam os rituais africanos que envolviam sacrifícios de animais, a presença de espíritos diabólicos, bebedeiras, comportamento grosseiro e a exploração econômica do cliente.

É difícil precisar o que vem a ser a Umbanda; além de ser uma religião sincrética desde o seu nascimento, Roger Bastide fala-nos da dificuldade em defini-la, por estarmos "em presença de uma religião a pique de fazer-se, ainda não cristalizada, organizada, multiplicando-se numa infinidade de subseitas, cada uma com seu ritual e mitologia próprios" (BASTIDE, 1985, p. 440).

No terreiro estudado também foi identificada essa liberdade de ação, não havendo qualquer tipo de obrigação à entidade federativa superior. Por isto a dificuldade em abordar a Umbanda como um sistema religioso que possui características gerais. Procurei, portanto, ressaltar neste trabalho aquilo que este terreiro tem de mais específico e original.

Neste sentido, considero pertinente abordar a questão do poder mágico que as entidades espirituais da Umbanda possuem, com o intuito de complexificar o debate das visões correntes entre aqueles que se dedicam a estudar este tema.

Existe uma teoria, usual para os pesquisadores da Umbanda, acerca do poder mágico que ass entidades espirituais possuem, na qual se constata a existência dentro 
do terreiro de uma inversão dos valores que reinam na ordem social dominante. Os "caboclos" e os "preto-velhos" são os detentores de maior poder e prestígio e, em geral, são os que comandam os rituais, ou seja, são os chefes espirituais das casas. Os "caboclos" são considerados como detentores deste poder por possuírem um conhecimento espiritual antigo, passado e cultuado ao longo de muitas gerações, estando mais próximos da natureza e de tudo que a liga ao conhecimento primordial do tempo mítico - o tempo que está presente nesse outro nível de existência, que chamam de astral ou mundo espiritual.

Assim também se situa a figura do "preto-velho" que, na visão do grupo estudado, está diretamente associada ao negro que veio da África escravizado, que já possuía um conhecimento espiritual e que ao longo dos anos lutou e sofreu para que a sua cultura fosse preservada e mantidos seus valores ancestrais que o ligam, da mesma maneira que os "caboclos", ao conhecimento espiritual que comanda o astral ou a vida depois da morte.

As "crianças" são também vistas como portadoras desse poder mágico. Por possuírem pouco tempo de vida na terra, sua mente ainda não está totalmente formada com os valores que reinam na sociedade dominante; ainda trazem dentro de si os valores de pureza do astral, que com o tempo vão sendo substituídos pelos valores sociais dominantes. Porém, as crianças não possuem posições de chefia dentro dos terreiros, por serem consideradas "infantis".

Os "exus" são os mais próximos da esfera humana. São, na visão do grupo estudado, espíritos de pessoas brancas que morreram recentemente, e que ainda estão muito presos aos valores materiais que reinam na sociedade. São também associados às energias mais básicas do homem, como a agressividade e a sexualidade. Mas são importantes justamente por fazerem esta ligação entre o mundo dos deuses e o mundo dos homens, mensageiros ou intermediários entre o céu e a terra.

É importante salientar que, apesar desta classificação ter sido feita inicialmente com base nas etnias e naquilo que cada uma possuía de mais representativo, não significa necessariamente que todo "caboclo" tenha sido índio e nem que todo "preto-velho" tenha sido preto. Na visão do grupo estudado, eles podem ter sido indivíduos de qualquer outra cor, mas que tiveram um contato próximo e/ou o conhecimento espiritual vindo sob aquela orientação.

Nesse sentido, meus dados de campo corroboram, até certo ponto, com a visão de alguns autores no que se refere à religião umbandista (VELHO, 1975; DA MATTA, 1979; BIRMAN, 1985): “[...] em que os fracos e socialmente despossuídos vão ter, através do santo poder mágico, sabedoria e força, virando pelo avesso as razões que legitimam a hierarquia social" (BIRMAN, 1985, p. 47). 
Discordo, entretanto, com base no depoimento dos meus entrevistados, com a concepção elaborada particularmente por Birman (1985) e Montero (1985), de que as "entidades" da Umbanda são consideradas "pouco evoluídas", tendo como parâmetro a imagem ideal do homem branco; e que, portanto, a subalternidade tem um valor positivo para a religião.

As "entidades" da Umbanda ocupam uma posição subalterna na sociedade ocidental moderna, mas nem por isso são vistas, pelos integrantes do grupo em estudo, como "pouco evoluídas". 0 que eles dizem ocorrer, na verdade, é o inverso. 0 homem branco não é colocado no topo da ordem evolutiva, como estas autoras afirmaram, mas inversamente na base, como foi percebido no terreiro em pauta: são os espíritos que menos esclarecimento espiritual possuem. Ressalto aqui o cuidado que esta afirmação deve conter se colocada em termos gerais e absolutos. Assim como foi dito acima, não são todos aqueles que possuem a cor branca, mas sim aquilo que foi agrupado como mais representativo à cultura branca ocidental. Neste sentido, a subalternidade não tem um valor positivo para a religião.

De acordo com a visão do grupo estudado, os espíritos que morreram e que não têm compreensão acerca do mundo espiritual, ao deixarem o corpo físico, sofrem por não mais possuírem vida na terra e ficam rondando como "almas penadas" aqueles que estão vivos, querendo, de forma obsessiva, se aproximar da luz que existe em todo ser vivo. A estas almas, este grupo estudado denomina de "eguns" ou "espíritos obsessores ou sofredores", eles estão situados nas posições mais inferiores da hierarquia dos terreiros. Em uma entrevista com a mãe-de-santo, ela nos esclarece:

Os "eguns" são os que estão deixando a matéria agora, é uma "egunzada" danada. Não se arrumam, não se afirmam, não é caboclo, não é marinheiro, não é boiadeiro, não é nada. De dez prepara um, de vinte, dois levantam e os outros ficam embaixo; são as "almas penadas"; os brancos vira tudo "alma penada". Claro, mataram os índios todos dessa terra, caçaram os negros lá da África, coitados, castigaram os negros. E vai morrer, tem mais é que ser "egum" mesmo, acho bom é pouco. Ahhh... tem que pagar bonitinho mesmo para poder levantar se quiser. E é isso. Agora quem está indo e voltando $e$ está indo novamente e se evoluindo, então é porque estão ligados na espiritualidade e não vão ser "egum" não.

\section{Breve Apresentação do Santo Daime}

A doutrina do Santo Daime, termo pelo qual seus adeptos designam esse sistema de crenças foi fundada em 1930 no Acre por Raimundo Irineu Serra (1892-1971), homem 
negro, natural do Maranhão, que aos vinte anos, atraído pela extração do látex da seringueira, no período do ciclo da borracha, integrou o fluxo de nordestinos que, fugindo da seca, migraram para a região amazônica.

Trabalhando como mateiro numa expedição de demarcação de fronteiras na região do Acre, chefiada pelo Marechal Rondon, Irineu conheceu a bebida milenar designada como ayahuasca através de um xamã. Bebida esta, preparada por meio do cozimento de plantas nativas da Floresta Amazônica, um cipó (o jagube, cientificamente denominado banisteriopsis caapi) e uma folha (chacrona, rainha ou mescla; $p$ sychotria viridis). 0 cipó é macerado pelos homens e a folha é tratada e selecionada pelas mulheres. Depois os dois são colocados em caldeirões de água fervendo durante 0 chamado "feitio" da bebida. Desta fervura, resulta o Daime (FERNANDES, 1986).

Através dessa bebida, utilizada em rituais mágico-religiosos por inúmeros grupos indígenas do continente americano desde tempos imemoriais, Irineu recebeu a revelação que fundamenta a doutrina do Santo Daime.

A bebida é, portanto, sagrada e para seus adeptos ela contém um "ser divino". Um ser divino que traz os ensinamentos da doutrina e que revela a existência de algo mais além da bebida, pois abre as portas da percepção para o autoconhecimento. É considerada um veículo de comunhão entre pessoas e seres espirituais. Podemos compará-la também a um sacramento da religião cristã (COUTO, 1988).

0 nome Daime vem do verbo Dar - dar para os que necessitam, dar para os que pedem. O Daime é identificado com entidades espirituais incaicas, precursoras na utilização desta bebida.

Irineu foi o fundador e principal líder do Santo Daime até 1971, quando faleceu. Sua missão foi a de Juramidam, entidade divina que segundo seus fiéis representa 0 retorno de Cristo e revela os ensinamentos da doutrina através dos "hinos". Esses ensinamentos são captados pelos adeptos do Daime durante a "miração", que é um estado de percepção extra-sensorial que permite ao indivíduo ter acesso a revelações sobre o seu próprio ser. Os "hinos" falam de questões vivenciadas individualmente; falam ainda de entidades cristãs, indígenas, africanas e outras próprias do sincretismo religioso (FERNANDES, 1986).

0 Daime foi trazido para o Rio de Janeiro na década de 1970 pelas mãos de um psicólogo residente nesta cidade, que em 1973 foi ao Peru em busca de novos métodos de investigação na área da psicologia. Era de seu intuito ir a lugares aonde pudesse estabelecer contatos com xamãs. Lá conheceu o Daime através da comunidade liderada pelo padrinho Sebastião. Depois de algum tempo de aprendizado dos ensinamentos da doutrina, teve a permissão para trazê-la para o sul. 


\section{O Terreiro de Umbanda em Pauta}

A maleabilidade que a religião umbandista possui ajustou-se bem aos anseios da mãe-de-santo deste terreiro, uma vez que ela tem como característica pessoal a rebeldia em obedecer a outros pais ou mães-de-santo. Desde os dezesseis anos ela possui um terreiro de Umbanda em que é a mãe-de-santo, pois sempre teve vontade de assumir a responsabilidade sozinha. Tem-se assim que praticamente tudo que ela aprendeu foi durante as sessões espirituais.

0 descobrimento dos trabalhos umbandistas dentro da espiritualidade que eu conheço é exatamente isso, ele vai sendo descoberto para você, ele vai vindo para você, as suas próprias entidades, os seus caboclos, ele vai instruindo você, você vai aplicando para você; está tudo aí, nós temos tudo é só ir trabalhando um pouquinho a gente para ir buscar: (mãe-de-santo)

Assim, conforme relatado pela mãe-de-santo, cada "entidade" faz parte de uma determinada falange ou linhagem e são essas falanges que compõem a unidade e estrutura básica da Umbanda. Por mais singular que cada terreiro possa ser a nível social, no astral as "entidades" que baixam nos terreiros estão ligadas ao comando de determinadas falanges espirituais. $\mathrm{E}$, dessa forma, podemos dizer que, neste caso estudado, o processo de socialização na Umbanda é feito diretamente com as entidades espirituais.

Da mesma forma, o Espiritismo de Alan Kardec também é uma religião elaborada com base nas respostas dadas pelos espíritos em sessões mediúnicas às perguntas feitas por Alan Kardec, o codificador da doutrina. É justamente este fato que torna o Espiritismo legítimo aos olhos de seus adeptos, ou seja, por não ser uma criação humana (CAVALCANTI, 1983).

0 mesmo ocorre com a religião do Santo Daime, elaborada a partir dos "hinos" (revelações vindas do astral) recebidos por seus adeptos através da "miração", que constitui a forma de contato entre o mundo dos homens e o mundo dos espíritos. Os "hinos" são todos codificados compondo os "hinários". Cada pessoa mais evoluída espiritualmente dentro desta religião possui o seu "hinário". E é com base nestes "hinários", que este sistema de crenças é fundamentado e socializado. Entretanto o Santo Daime ainda está se fazendo, uma vez que seus adeptos estão a cada dia recebendo novos "hinos". Nesse sentido, ele se aproxima da Umbanda, pois a cada dia novos ensinamentos vão sendo ministrados pelos chefes espirituais dos terreiros e novas maneiras de se praticar a Umbanda vão sendo criadas. Diferente do Espiritismo, onde se tem uma doutrina fechada, cujos ensinamentos já se encontram escritos e codificados. 
A união entre este terreiro de Umbanda e o Santo Daime decorreu inicialmente da aproximação do marido da mãe-de-santo com o Daime. Vale a pena ressaltar que as pessoas que freqüentam este terreiro e o Daime têm muito em comum, permeiam os mesmos espaços e grupos sociais - enfim, fazem parte da mesma rede social. A mãe-desanto acompanhou seu marido e, no Daime, foi-lhe revelada a aproximação que seu caboclo tem com essa religião:

o Caboclo [Tupinambá - chefe espiritual do terreiro] tem um trabalho para fazer com eles [fiéis do Daime], se eles são médiuns, eles não são desenvolvidos, eles são conhecedores da espiritualidade, mas não com consciência, eles sabem que existe a incorporação, mas não estão se preparando para isso e o trabalho do Caboclo é preparar esses médiuns. Os caboclos vêm trabalhar com o Daime curar, usar o Daime para a cura (...) Quando o Caboclo andou por aqui, (...) não tem nem dúvida que ele deve ter acompanhado o Mestre Irineu, ele conta história do Mestre com a maior clareza. (mãede-santo)

Em Lumiar, município de Nova Friburgo, RJ, já existia um terreno onde iria ser construída uma casa, que teria o nome de "Lua Branca", em que se congregariam as duas religiões. Em 1988, em uma sessão espiritual realizada nesse espaço, firmou-se a união entre as duas correntes e o compromisso da construção da casa, que serviria tanto como terreiro de Umbanda quanto como igreja do Santo Daime. Em dezembro a casa estava pronta e, finalmente, a união foi celebrada.

$\mathrm{Na}$ "Lua Branca" são realizadas as sessões da Umbanda e do Santo Daime separadamente, isto é, ambas mantém a sua forma original de realização e as suas autenticidades. 0 dado novo acrescentado ao ritual da Umbanda é a oferta de uma pequena dose da bebida do Daime, para aqueles que desejarem, durante as sessões ordem ministrada pelo chefe espiritual da casa, caboclo Tupinambá. Além disto, também existe a permissão de cantar as músicas ("hinos") do Santo Daime nas sessões de Umbanda.

As repercussões dessa união junto às pessoas que freqüentam o centro de Umbanda foram as mais diversas. Alguns acreditaram que poderia haver uma troca favorável, que tanto a Umbanda teria a aprender com o Daime, quanto o contrário; para outros, pude perceber que a aproximação era indiferente, e que continuariam freqüentando a Umbanda independente da união com o Daime; mas muitos chegaram mesmo a se afastarem do centro por não concordarem com a união.

A grande maioria das pessoas que freqüenta este terreiro é de indivíduos na faixa etária entre 25 e 55 anos, morador da cidade do Rio de Janeiro ou da região serrana de Nova Friburgo, que, em geral, não foi socializada dentro da Umbanda ou do 
Santo Daime, mas que por opção individual chegou a estes sistemas religiosos. São indivíduos pertencentes às camadas médias intelectualizadas e/ou artísticas, e "com experiências existenciais que 68 consagrou e resumiu no imaginário histórico; indivíduos, portanto, "liberados", "libertários", "abertos", e críticos da tradição" (SOARES, 1990, p. 1,2).

É preciso, portanto, buscar nos movimentos da juventude dos anos 1960 os elementos que compõem o universo destes indivíduos: 0 estilo de vida difundido pela "contracultura", marcado pela recusa de um modo de vida convencional, calcado no racionalismo, no cientificismo e no materialismo. Em contraposição a isto, valorizam a sensibilidade, os elementos vindos da natureza, a experimentação vivida no presente, no deixar fluir, onde o corpo e os sentimentos são mais valorizados do que a mente racional.

\section{As Práticas Terapêuticas Presentes NA UMBanda E no Santo Daime}

Refletir acerca das práticas terapêuticas pareceu-me importante porque constatei que neste terreiro grande parte dos seus freqüentadores procura essa religião como meio para experimentar práticas espirituais de cura. Outra razão que me deteve na questão da cura foi o fato da mãe-de-santo deste terreiro tê-la como meta principal de seu trabalho. Nas suas próprias palavras:

A vontade que eu sinto é de juntar todos que dizem: eu curo, eu trabalho com a cura. Seja ele com a água, seja ele com o cristal, qualquer coisa (...) Quem se apresentar com a cura, seja bem vindo.

As práticas terapêuticas foram abordadas nessa pesquisa dentro de uma perspectiva que privilegia os aspectos psicossomáticos da doença, configurando-se como práticas que possibilitam ao indivíduo um maior autoconhecimento e, portanto, maior integração com a sociedade e com o cosmos. Isto pode ser revertido em saúde e prevenção de doença, como será explicitado a seguir.

0 enfoque central desta abordagem recai sobre a noção de "experiência espiritual", uma vez que, conforme descrito por Ioan Lewis (1977), todo encontro transcendental é único e só pode ser apreendido através da experiência pessoal. Neste sentido, como pude perceber no grupo estudado, a possibilidade do encontro entre os dois mundos - espiritual e material - se dá através da experiência espiritual vivida singularmente por cada praticante, em que o corpo recebe a função de mediar a dicotomia entre estas duas esferas. 
$\mathrm{Na}$ Umbanda, a mediunidade é a experiência espiritual por excelência, constituindo-se o eixo central que articula todas as suas formas de expressão. Eu não diria que a possessão (ou mediunidade de incorporação) ocupa esse centro aglutinador, pois ela é uma das formas da mediunidade - a mais expressiva e que possui o maior peso no culto umbandista - mas também existem outras formas, tais como a psicografia, a clarividência, a clariaudiência e a forma mais sutil da mediunidade, segundo o próprio grupo, que é a intuição.

Todavia em qualquer destes tipos de mediunidade, o corpo é sempre tido como um "aparelho" para que as forças espirituais possam se expressar. Para tanto, esse mesmo corpo deve estar em boas condições físicas e materiais, para que possa "servir de canal" ou ainda "dar passagem" às manifestações sobrenaturais. Além disto, o corpo deve ser preparado de acordo com os preceitos de purificação adotados pelo grupo, denominados por Van Gennep de "ritos de passagem", importantes por realizarem a passagem da esfera profana para a instância sagrada. Esse momento de purificação é permeado por preceitos e obrigações que devem ser rigidamente executados; pois assim, como afirmou Mary Douglas (1976), tudo aquilo que se situa entre fronteiras classificadoras quase em toda parte é considerado "contaminador" e "perigoso".

Os integrantes do grupo se referem ao desenvolvimento mediúnico como um processo terapêutico: em cada passo, busca se auto-conhecer. Através de seu ritual, seus integrantes vivenciam experiências, que os coloca em contato com diferentes sentimentos que compõe o seu ser, conforme o relato de uma de minhas entrevistadas:

0 trabalho na Umbanda é extremamente terapêutico: em uma gira você vive a sua criança que ajuda você a se alegrar na sua vida; você vive a força do exu que te ajuda, te ensina, bota em prática seu descarrego das forças mais básicas da sexualidade; você vive Oxum que é a coisa da limpeza; então você mexe com várias facetas suas em uma gira, num girado, em um dia; também a força do velho que vem com a coisa da sabedoria, você vai atualizando tudo isso, é muito rico.

Ao mesmo tempo em que os indivíduos envolvidos com essas diferentes práticas terapêuticas mesclam ingredientes diversos em busca de uma maior compreensão de si e do mundo que os rodeia, eles também encontram nesse terreiro um espaço onde podem entrar em contato com outros tantos tipos de práticas de cura advindo da diversidade social e cultural de seus freqüentadores. Assim, ainda de acordo com esta entrevistada:

Eu tenho um desejo de socializar mais a psicologia e estes trabalhos espirituais são uma opção terapêutica para o terceiro mundo, mais popular, muita gente participa. 
Você vai receber uma informação de um preto-velho e vai levar uma informação de um trabalho terapêutico que vem lá dos Estados Unidos. Abre um espaço de trocas que eu acho muito importante. Você vai aprender o lance das ervas, mas vai levar o lance da psicanálise. Existe um encontro de classe média com pessoas que vêm de uma classe mais baixa, que sem a gente sentir a troca já está rolando, só pelo fato daquelas pessoas estarem convivendo.

Para os integrantes do grupo em estudo, o corpo humano é visto como um microcosmo inserido no macrocosmo, que é a natureza como um todo. Os elementos da natureza são as irradiações divinas do poder centralizador (que corresponde a noção de Deus): são os chamados "orixás". Em cada ser humano existem todos os elementos que compõem a natureza: minerais, vegetais, a água, o vento etc. Cada indivíduo possui uma proporção maior de um desses elementos do que dos outros, o que determina as afinidades. Por exemplo, se tem mais mineral no corpo, é mais ligado à pedra e às entidades que a representam.

0 corpo, portanto, se encontra diretamente relacionado a uma divindade e, por extensão a um dos elementos naturais e demais coisas a ela associadas (BARROS; TEIXEIRA, 1989).

Do mesmo modo, o corpo do adepto é microcosmo, onde estão presentes linhagens e espaços, história do grupo e dimensões do mundo (...) Preparar este corpo, torná-lo apto a manifestar a presença divina, situá-lo adequadamente no tempo e no espaço, é uma aprendizagem de todos os instantes. (AUGRAS, 1986, p. 04).

Assim, de acordo com o grupo estudado, cada indivíduo abriga em seu corpo um lado físico/material e um lado espiritual. Se por um lado, ele é veículo para as divindades, por outro, ele é expressão da individualidade humana, portando em si a marca da vida social.

Neste sentido, como apontaram Barros e Teixeira em seus estudos nas comunidades de Candomblé:

A saúde, condição inalienável do ser humano, é, ao mesmo tempo, um bem concedido pelos deuses, necessitando ou supondo dádivas constantes que atualizem e renovem a relação harmoniosa - a unidade - entre o "aiê" e o "orum" - entre 0 mundo dos homens e o mundo dos deuses (...) A pessoa é vista como um ser social total, possuidora de um corpo identificado não a uma máquina cujos componentes estão avariados ou quebrados, mas como personagem de uma história, o que lhe confere unicidade dentro do drama social do qual participa. Não são figuras ou personagens anônimos, mas seres portadores de identidade. (BARROS; TEIXEIRA, 1989, p. 32). 
0 grupo estudado entende que a doença, seja física ou espiritual, provém do espírito. 0 corpo físico é apenas um mataborrão ou um fio terra ou ainda, uma descarga do espírito. 0 que dá vida ao corpo é o espírito. As causas das doenças podem ter diferentes origens: físicas, psicológicas, sociais ou espirituais. Um dos grandes motivos, apontado pelo grupo, para a ocorrência das doenças deve-se à falta de harmonia ou ao desequilibrio do indivíduo em relação ao meio ambiente, ou seja, em relação à ordem e às leis que regem 0 universo.

De acordo com a visão do grupo, no homem estão presentes todas as "energias" que vibram no universo, variando de intensidade e de qualidade conforme o indivíduo. Quando uma pessoa vive realçando apenas certo tipo de "energia", vibra muito nesse sentido, sucumbindo outras "energias" que ficam paradas no seu corpo. Essa pessoa, então, se desarmoniza com o todo e tem a doença característica daquela "energia". Assim, quando uma pessoa é muito irada ou muito raivosa, e cultiva esse sentimento exacerbado, descargas tóxicas são despejadas no seu organismo e ele possivelmente ficará combalido. Ao longo dos anos, os distúrbios vão aparecendo e, sendo somatizados, começam a degenerar determinados órgãos ou o funcionamento do organismo como um todo. Segundo depoimento de um dos participantes do grupo é somente neste estágio que a medicina ocidental contemporânea (biomedicina) é capaz de detectar a doença.

Na maior parte dos trabalhos espirituais que visam a cura, o que se pretende é atingir o corpo etéreo ou a aura do indivíduo. De acordo com um dos entrevistados:

A aura é a manifestação do estado de saúde, de harmonia do conjunto do corpo. Videntes fazem leitura, diagnóstico de doença pela aura, pela intensidade do seu brilho, pelas cores e aí vêse aquele organismo está saudável ou não, está mais equilibrado ou menos equilibrado (...) A aura é a manifestação de seu estado geral/psicológico e do estado orgânico (...) São camadas energéticas, é a transpiração mais a nível sutil/energético.

Conforme me foi relatado pela mãe-de-santo, a doença antes de chegar no corpo físico, já pode ser vista no corpo etéreo pelas entidades espirituais ou pelos videntes que são capazes de ver a aura das pessoas. Assim, existem determinados rituais de cura que visam promover uma limpeza no corpo etéreo, dando-lhe proteção para que este fique imune à penetração de organismos maléficos (BARROS; TEIXEIRA, 1989). Este é 0 caso do "sacudimento", ritual que foi comparado pela mãe-de-santo a uma vacina que imuniza contra a doença, na medida em que purifica o corpo e afasta os elementos causadores da doença.

As doenças provocadas por causas estritamente espirituais são em geral àquelas causadas por "espíritos obsessores" que ficam atrás, obsessivamente, da "luz" de determinadas pessoas, retirando-lhes as suas "energias". Existem também doenças 
provocadas pela mediunidade não-desenvolvida. A mãe-de-santo deste terreiro considera que muitos casos de loucura ou esquizofrenia podem ter sido ocasionados por uma possível mediunidade não-desenvolvida.

É consensual para o grupo em estudo que a cura começa com a tomada de consciência da doença. Para este grupo, a doença não é sinônimo de morte e destruição, pelo contrário, é de limpeza e purificação. A doença configura-se como uma série de transformações no corpo que, bem direcionadas, podem ser revertidas em saúde.

A cura depende em grande parte do paciente estar preparado para recebê-la. Esse é um ponto essencial para o pensamento espírita e também para o grupo pesquisado. Se o paciente não estiver em condições de merecer determinada cura, as graças divinas não the auxiliarão. De acordo com o depoimento da mãe-de-santo:

Enquanto a gente está aqui trabalhando, eles estão aí. Agora, eles chegam que me dá uma aflição, olha a pessoa, fica assim "oohhhh" e vai embora. Vocêpensa que eles vão fazer uma cura e eles não fazem, porque a missão não é esta, eles não conseguem chegar, porque a pessoa tem um campo vibratório negativo, tem uma dúvida, tem um medo, tem um não sei o que; então eles só ficam olhando e não se aproximam. É por aí que entram as curas. Você não manda no astral, mas nunca. Você fica aqui, se tiver condição de cura, eles curam, se não tiver, eles pegam esses recursos que tem aqui e vai curar um que está lá não sei aonde.

Para os adeptos do Santo Daime, que freqüentam tanto os rituais do Daime quanto o terreiro em pauta, o corpo também é percebido como uma manifestação da ação sobrenatural. 0 corpo deve ser preparado, em todos os instantes da vida, em função das necessidades que o "trabalho espiritual" lhe impõe. Acredito que a marca que a esfera espiritual imprime nos corpos dos fiéis do Santo Daime é ainda mais incisiva que a marca impressa nos fiéis que freqüentam somente este terreiro de Umbanda, uma vez que ultrapassa a esfera do ritual propriamente dito, estendendo-se à esfera da vida cotidiana. Dessa maneira, a alimentação deve seguir certos preceitos, sendo recomendado não ingerir carne e bebida alcoólica. No vestuário também recomendam que as mulheres não usem calça comprida, apenas saia, e que o comprimento seja abaixo do joelho. Em geral, o tamanho do cabelo para as mulheres tende a ser comprido e, para os homens, curto, mas a barba tende a ser grande. Geralmente os fiéis do Daime mantêm certo conservadorismo em relação aos seus corpos; a sexualidade é mais cerceada e, inclusive, existem restrições a manter relações sexuais durante determinados dias, antes e após os rituais.

Para seus praticantes, o Santo Daime é visto como um "caminho" de autoconhecimento, sendo obtido através da ingestão da bebida, que possui elementos 
psicoativos - enquadrando-se nas chamadas "plantas do saber" - e que se constitui em um alimento para a alma. A bebida do Daimeé vista, nesse sentido, como um combustível para a alma poder transportar-se a regiões mais distantes, ampliando os níveis da percepção (ALVERGA, 1984).

Na prática, esse conhecimento de si dá-se por meio da "miração". Para aquele que se inicia no Santo Daime, esse processo muitas vezes é vivenciado sob a forma de uma catarse, dando-se também a nível físico, podendo ocorrer vômitos, diarréias ou tremedeiras. Isto é explicado como sendo um processo de limpeza, pois, segundo seus adeptos, para que o indivíduo possa atingir o estágio da "miração" é importante que 0 corpo esteja limpo, tendo ainda o efeito psicológico no sentido de descarregar, botar para fora aquilo que não serve mais a si mesmo (ALVERGA, 1984).

É comum às pessoas que se iniciam no Santo Daime relatarem experiências em que a sensação da morte é vivenciada. O Daime parece colocar essa questão em que é necessário morrer para depois renascer. De acordo com seus adeptos, tudo que entra em desacordo com os princípios da doutrina aos poucos vai desaparecendo: vícios, comportamentos negativos, más companhias. Alex Polari de Alverga, um dos primeiros a trazer o Daime para a região sul do país, e um dos principais responsáveis dentro dessa religião pela aproximação com o terreiro de Umbanda em estudo, assinala em seu livro:

A terapia espiritual é valorativa. Funda-se na existência de uma verdade revelada que, uma vez seguida, conduz ao caminho da harmonia, da saúde e dos determinantes do mal. (...) A cura não pode ser, nesse caso, nem a repressão, nem a complacência, nem a mera consciência verbalizada. É um esforço, no sentido de "retomar as rédeas do ser". De praticar o Bem e a Justiça, de ser harmônico com as leis do Universo. Antes de ser uma terapia, é uma pedagogia espiritual. (ALVERGA, 1984, p. 230).

Nesta visão ele acentua o caráter de revelação contido na cura. Segundo o autor, a "miração" dá ao indivíduo a possibilidade de conhecer-se a si mesmo e de saber qual o caminho a seguir. A cura é, nesse sentido, um aprendizado da verdade divina e das leis que regem o universo Este aprendizado vai sendo apresentado ao adepto por meio das revelações contidas nas "mirações", ou seja, o conhecimento vem através da própria experiência vivenciada por cada um.

Para seus adeptos, a "miração" difere bastante da "alucinação". 0 Daime, portanto, não é caracterizado como um alucinógeno, mas ao contrário, é visto como produto da expansão da consciência, advindo de um estado de percepção extra-sensorial. As "mirações" são associadas às visões, segundo seus adeptos, a sensação é de êxtase. 0 indivíduo fica lúcido durante a miração, sabe o que está acontecendo, lembra-se do 
que viu e sentiu, diferente da alucinação, onde 0 indivíduo não sabe se o que está acontecendo é verdade ou não (ALVERGA, 1984). Como assinala um de meus entrevistados:

A "miração" é um resgate de coisas que já se passaram, aflorando na memória, coisas que estão apagadas ou guardadas no arquivo do inconsciente e que vem à tona, explicando situações atuais. Isto vem dentro do "trabalho espiritual" de diversas formas: lembranças, imagens, como num sonho tão real que você pensa que está vivendo a realidade.

A função corporal no ritual do Santo Daime possui um papel muito importante. Todas as posições e maneiras de se comportar dentro do ritual são prescritas e controladas por determinados membros do grupo, chamados de "fiscais". A "fiscalização" é necessária, segundo os integrantes do grupo em estudo, para que a ordem do ritual seja mantida, dando sempre a mesma referência, a nível material e social, para aqueles que estão absorvidos por outros estados de consciência. Neste sentido é interessante a abordagem feita por uma de minhas entrevistadas:

0 ritual do Daime tem um trabalho corporal muito importante: você está batendo com os pés no chão, você está cantando, você está olhando porque você está lendo, você está ouvindo para cantar junto com as outras pessoas; então, puxam os teus sentidos para 0 aqui e 0 agora e muito fortemente, e isto dá uma referência corporal para você poder fazer viagens tão profundas.

\section{Novas Formas de Religiosidade Presentes neste TERREIRo DE UMBANDA}

Os indivíduos que procuram por este terreiro têm em comum o fato de estarem buscando uma prática que lhes permita conhecerem-se a si mesmo por meio da experiência mística que se vivencia no decorrer do desenvolvimento espiritual, através da "re-ligação" com o todo (Deus). A religião torna-se, deste modo, apenas a ponte que viabiliza a re-ligação e não o fim em si; para esses praticantes o importante é encontrar a divindade dentro de si e não tanto se manter fiel a uma determinada religião.

Vejo que para os praticantes que me proporcionaram as fontes para o meu estudo, o sagrado está dentro de cada indivíduo, ou seja, existe uma verdade transcendente que é igual à verdade interior. Esta totalidade sagrada, denominada de Deus, está no universo/ natureza, mas também está dentro de cada um, conforme demonstram os depoimentos dos meus entrevistados: 
Porque a religião é um passo só, é a re-ligação, o resto acontece depois (...) É a coisa de encontrar a divindade dentro de você mesmo, encontrar a sua luz. Por que a gente não foi criado à semelhança de Deus? Então a gente tem o divino.

A gente tem a centelha divina, é esse espírito, é essa coisa que a gente trabalha no espiritual, que está buscando essa aproximação com esta centelha, que é a luz, que é a sanidade, que é o equilibrio, que é a força em si.

Nesse sentido, Deus não se configura como uma verdade absoluta na qual os homens têm que se submeter, mas como uma verdade absoluta que se revela, enquanto vivência, no próprio corpo dos homens. A religião configura-se, assim, como uma ponte que auxilia o indivíduo a se conectar com o sagrado. Vale a pena ressaltar que esta ligação homem/sagrado ou indivíduo/cosmos para se manifestar não necessita passar pelo crivo da religião; muitos homens vivenciam esta ligação com bastante intensidade sem nunca terem entrado em uma igreja, terreiro, ou qualquer espaço ligado a uma religião específica.

Essa mesma sacralidade, que pode ser encontrada tanto no corpo dos indivíduos como no cosmos, é que dá o tom no equilíbrio das relações sociais, configurando-se como o fio condutor que perpassa todos os indivíduos, dando um sentido comum às suas relações sociais.

Neste universo pesquisado, a inserção em uma crença religiosa específica pode ser ou não consequiência dessa procura; agrupando-se a um determinado ritual podese aprender mais e assim aprofundar o conhecimento espiritual, mas de modo algum ela se torna o fim da jornada.

Uma de minhas entrevistadas, ao ser perguntada sobre qual a sua religiosidade, responde:

Procuro desenvolver um aprofundamento de um estudo da espiritualidade buscando um ponto espiritual mais universal, aquele ponto que está em todos os lugares, em todas as pessoas e na natureza. Tentar fazer esta busca não sozinha, mas junto com outras pessoas. Para conseguir isto a gente precisa, em alguns momentos, dar um contorno a esta busca, buscar desenvolvendo uma linguagem, mas sempre sabendo que esta linguagem é uma linguagem e que existem outras e outras. No momento eu estou em um estudo na Umbanda.

Ou ainda, nas palavras de outro entrevistado:

A sensibilidade do homem reflete a divinitude. A minha religiosidade é viver. Quando você fala em religião ou religiosidade você está colocando parâmetros, e eu acho que a religião é a coisa de vida, eu vejo religião em uma pessoa comum, andando na rua eu vejo a religião. 
Estar na Umbanda por algum tempo não denota, necessariamente, um vínculo frágil ou de pouco empenho para com a religião, este vínculo é sentido como um compromisso, que inclui dedicação, trabalho, esforço, aprendizado, disciplina, ciente de seus deveres e obrigações para com o grupo e o respeito à hierarquia presente na casa. E indica, ao mesmo tempo, o caráter individual deste vínculo (SOARES, 1989).

É interessante ressaltar, neste sentido, o modo como as pessoas se relacionam com "as religiões", no plural. No horizonte do misticismo alternativo a pluralidade ocupa um lugar único. Luiz Eduardo Soares, ao analisar este tema, sugere:

Esses indivíduos são andarilhos que fazem da própria busca a essência da sua utopia e a natureza de sua devoção. 0 religioso alternativo é também um andarilho. Faz parte de sua agenda um deslocamento permanente entre formas de "trabalhar" a espiritualidade, em nome de uma busca sempre renovada de experiências místicas. Nada mais coerente, portanto, que a inconstância e a volubilidade. A devoção a crenças e rituais se dá, geralmente, sob o signo da experimentação. (SOARES, 1989, p. 24-25).

A revalorização da experiência religiosa recoloca a questão da fé posta de lado por algum tempo entre estes indivíduos de camadas médias, que fazem parte ou ao menos têm acesso à elite e ao saber dominante, e que agora optam por ingressar em determinados sistemas religiosos, "com fé" na realização efetiva de seus desejos.

\section{Considerações Finais}

Apesar das diferenças existentes entre estes dois sistemas de crenças, acredito que a união consumada e que assegura a ação coletiva deste grupo foi possível devido ao fato de que as ideologias e as práticas do Santo Daime e da Umbanda têm muitos pontos que se aproximam, e que permitem o compartilhamento, de forma sincrética, do mesmo ritual.

A natureza é, para as duas, a referência máxima, configurando-se como a emanação do poder divino: os "orixás" e a utilização de ervas para banhos, chás e beberagens, num caso, e a bebida, preparada através do cozimento de elementos extraídos da natureza, no outro.

As práticas terapêuticas utilizadas no terreiro em pauta, que permeiam o universo tanto da Umbanda quanto do Santo Daime, estão em conformidade com a visão de mundo que atribui às representações da natureza poder e saber reveladores dos ensinamentos divinos, sendo fonte de medicamentos e tratamentos para os diversos tipos de doenças. Esses ensinamentos divinos são, por sua vez, de acordo com os dados apresentados ao longo do artigo, encontrados também dentro de cada indivíduo, a partir 
do momento em que ele se volta para dentro de si, entrando em contato com a sua própria natureza, isto é, com seus pensamentos e sentimentos profundos e que compõem o seu ser. Sendo assim, é consensual aos dois sistemas religiosos a premissa de que 0 conhecimento se dá por meio da experiência individual, vivida singularmente por cada praticante, pois, para seus adeptos, o indivíduo é portador da "centelha divina", bastando querer buscar este conhecimento dentro de si.

\section{REFERÊNCIAS}

ALVERGA, Alex Polari de. Viagem ao Santo Daime: o livro das mirações. Rio de Janeiro: Rocco, 1984.

AUGRAS, Monique. A construção simbólica do corpo no Candomblé do Rio de Janeiro. In: CICLO DE ESTUDOS SOBRE O IMAGINÁRIO, Simbolismo nas Religiões, 4., 1986, Recife.Anais... Recife: Centro de Pesquisas sobre o Imaginário da Fundação Joaquim Nabuco, 1986.

BARROS, José Flávio Pessoa de; TEIXEIRA, Maria Lina Leão. 0 código do corpo: inscrições e marcas dos orixás. In: SEMINÁRIO DO INSTITUTO DE FILOSOFIA E CIÊNCIAS SOCIAIS E HUMANAS DA UERJ, 1989, Rio de Janeiro.

BASTIDE, Roger. As religiões Africanas no Brasil. São Paulo: Livraria Pioneira, 1985.

BIRMAN, Patrícia. O que éa Umbanda. São Paulo: Abril Cultural: Brasiliense, 1985. (Coleção Primeiros Passos, 34).

BROWN, Diana. Uma história da Umbanda no Rio. In: Umbanda e Política. Rio de Janeiro: ISER, 1985.

CAVALCANTI, Maria Laura Viveiros de Castro. 0 mundo invisivel. Rio de Janeiro: Zahar, 1983. COUTO, Fernando de La Rocque. Santos e Xamãs: estudo do uso ritualizado da ayahuasca por caboclos da Amazônia e, em particular, no que concerne sua utilização sócio-terapêutica na doutrina do Santo Daime. 1988. Dissertação (Mestrado) - Universidade de Brasília, Brasília. COSTA, Jurandir Freire. A crença na psicanálise. Revista Religião e Sociedade, Rio de Janeiro, v. 11, n.2, p.4-29, 1984.

DAMATTA, Roberto. Carnavais, Malandros e Heróis: para uma sociologia do dilema brasileiro. Rio de Janeiro: Zahar, 1979.

DOUGLAS, Mary. Pureza e Perigo. São Paulo: Perspectiva, 1976.

FERNANDES, Vera Fróes. História do povo Juramidam: introdução à cultura do Santo Daime. Manaus, SUFRAMA, 1986. 
LEWIS, Ioan M. Êxtase religioso: um estudo antropológico da possessão por espírito e do xamanismo. São Paulo: Perspectiva, 1977.

LOYOLA, Ma Andréa. Médicos e Curandeiros: conflito social e saúde. São Paulo: Difel, 1984.

LUZ, Madel Therezinha. A arte de curar versus a ciência das doenças. São Paulo: Dynamis, 1996.

MENEZES, Eduardo D. B. de. Novas formas de religiosidade: a crença nas paraciências. In: ENCONTRO ANUAL DA ANPOCS, 12., 1988, Águas de São Pedro. Anais... Águas de São Pedro, 1998.

MONTERO, Paula. Da doença à desordem: as práticas mágico-terapêuticas na Umbanda. Rio de Janeiro: Edições Graal, 1985.

SOARES, Luiz Eduardo. Religioso por natureza: cultura alternativa e misticismo ecológico no Brasil. In: Leilah Landim. (0rg.). Sinais dos Tempos, Tradições Religiosas no Brasil: ISER, 1989.

. O Santo Daime no contexto da nova consciência religiosa. Rio de Janeiro: ISER, 1990 (mimeo).

VELHO, Gilberto. Projeto e metamorfose: antropologia das sociedades complexas. Rio de Janeiro: Jorge Zahar, 1994.

VELHO, Yvonne Maggie. Guerra de Orixá: um estudo de ritual e conflito. Rio de Janeiro, Zahar, 1975. 